\title{
ANALISIS PENGGUNAAN UNINTERRUPTIBLE POWER SUPPLY (UPS) TERHADAP PEMBEBANAN DAYA STASIUN RELAY RAJAWALI TELEVISI PALEMBANG

\author{
SUBIANTO
}

\author{
Dosen Tetap Yayasan pada Program Studi Teknik Elektro \\ Fakultas Teknik Universitas Palembang
}

\begin{abstract}
ABSTRAK
Semakin besar kekuatan pemancar, maka kualitas siaran yang dihasilkan pun lebih baik, dan jangkauan siaran pun menjadi lebih luas. Begitu juga sebaliknya. Namun, kekuatan pemancar juga harus disesuaikan dengan luas wilayah, mengingat saat ini telah banyak berdiri stasiun televisi lokal.

Bila terjadi kegagalan atau mati server sebentar saja dapat menyebabkan kerugian yang tidak sedikit bagi perusahaan. Oleh karena itu diharapkan dapat menganalisa kapasitas daya UPS terhadap pembebanan server-server dalam upayanya untuk mengantisipasi terjadinya kegagalan listrik di Stasiun Relay Rajawali Televisi Palembang.

Dari penelitian yang dilakukan diperoleh hasil bahwa UPS load di Stasiun Relay Rajawali Televisi Palembang sebesar 35,9\% (terpakai 25,128 kVA dari $70 \mathrm{kVA}$ ), hal ini berarti masih dapat dilakukan penambahan beban/server yang lebih banyak lagi. UPS rating di Stasiun Relay Rajawali Televisi Palembang memiliki daya yang lebih besar dari UPS rating ideal (oversizing UPS). Ini dilakukan untuk mendapatkan runtime yang lebih lama dan jika ada penambahan server.
\end{abstract}

Kata kunci : UPS (Uninterrruptible Power Supply), server, load, runtime

\section{PENDAHULUAN}

\subsection{Latar Belakang ${ }^{[5]}$}

Stasiun relay adalah antena pemancar untuk penyiaran radio ataupun televisi yang dibangun di beberapa wilayah tertentu untuk memancarkan siaran gelombang elektromagnetik secara berantai diwilayah yang di tuju sebagai target siarannya. Stasiun relay tidak dapat memproduksi dan menyiarkan sendiri siarannya. Melainkan hanya menerima dari stasiun induknya yang biasanya berada di kota besar/padat penduduk. Hal inilah yang diinginkan dalam Undang-undang penyiaran No 32 tahun 2002 agar stasiun televisi swasta nasional memanfaatkan stasiun televisi lokal sebagai jaringannya yang berfungsi sebagai stasiun relay.

Kegiatan operasi pemancar berlangsung terus setiap jamnya dan kegagalan atau mati listrik sangat tidak diharapkan. Untuk mengantisipasi mati listrik digunakan Uninterruptible Power Supply (UPS) yang dapat membuat server-server dan transmitter di Stasiun Relay Rajawali Televisi Palembang untuk tetap hidup selama beberapa waktu saat terjadi listrik mati sampai akhirnya listrik di-supply oleh generator set (genset) atau sampai akhirnya listrik hidup normal kembali (atau di-supply oleh PG\&T). Karena bila terjadi kegagalan atau mati server sebentar saja dapat menyebabkan kerugian yang tidak sedikit bagi perusahaan. Oleh karena itu, melalui penelitian ini diharapkan dapat menganalisa kapasitas daya UPS terhadap pembebanan server-server dalam upayanya untuk mengantisipasi terjadinya kegagalan listrik di Stasiun Relay Rajawali Televisi Palembang.

\subsection{Tujuan Penelitian}

Adapun tujuan dari penelitian ini adalah sebagai berikut :

1) Mengetahui kemampuan daya tahan UPS yang ada di Stasiun Relay Rajawali Televisi Palembang saat terjadi mati listrik agar dapat mengukur manfaat dari UPS.

Analisis Penggunaan Uninterruptible Power Supply (Ups) Terhadap Pembebanan Daya

Stasiun Relay Rajawali Televisi Palembang

(Subianto) 
2) Mengetahui kesesuaian kapasitas beban di Stasiun Relay Rajawali Televisi Palembang (berupa server yang ada yang sudah terhubung ke UPS) terhadap kemampuan/kapasitas daya UPS.

\subsection{Manfaat Penelitian}

Melalui penelitian ini diharapkan dapat memberi manfaat atau kegunaan bagi pengembangan khazanah ilmu pengetahuan khususnya yang berhubungan dengan Uninterruptible Power Supply (UPS), dan dapat mengetahui tingkat kegunaan Uninterruptible Power Supply (UPS) terhadap pembebanan daya yang dibutuhkan perusahaan.

\subsection{Ruang Lingkup Penelitian}

Penelitian ini meliputi penggambaran tingkat kegunaan Uninterruptible Power Supply (UPS) terhadap pembebanan daya yang ada di Stasiun Relay Rajawali Televisi Palembang.

\section{TINJAUAN PUSTAKA}

\subsection{Uninterruptible Power Supply (UPS) ${ }^{[1],[2] \&[3]}$}

Salah satu peralatan pendukung yang dapat digunakan untuk melindungi berbagai perangkat vital dari ganggguan listrik adalah Uninterruptible Power Supply (UPS). Alat ini dapat berfungsi sebagai stabilizer terhadap terjadinya gangguan dan menjadi sumber daya cadangan (backup) apabila terjadi gangguan pemutusan aliran daya dari penyedia suply daya utama. Di sisi lain, kinerja UPS terhadap berbagai jenis beban dan berbagai tingkat pembebanan belum tentu sama. Kinerja tersebut dapat dipandang dari dua kondisi, yaitu kondisi normal dimana UPS berperan sebagai stabilizer terhadap gangguan dan kondisi darurat pada saat terjadi pemutusan aliran listrik dari penyedia suply daya utama dimana UPS berfungsi sebagai backup suply daya sementara.

UPS adalah salah satu cara dari seorang arsitektur jaringan untuk menjaga keamanan di sisi availability. UPS sendiri merupakan singkatan dari kata Uninterruptible Power Supply yang artinya adalah sebuah alat elektronik yang fungsi utamanya adalah sebagai penyedia listrik cadangan pada komputer, Data Center, dan hal-hal pentingan lain.

\subsection{Fungsi UPS ${ }^{[4]}$}

Fungsi utama dari UPS adalah:

a. Dapat memberikan energi listrik sementara ketika terjadi kegagalan daya pada listrik utama.

b. Memberikan kesempatan waktu yang cukup untuk segera menghidupkan genset sebagai pengganti listrik utama.

c. Memberikan kesempatan waktu yang cukup untuk segera melakukan back up data dan mengamankan sistem operasi (OS) dengan melakukan shutdown sesuai prosedur ketika listrik utama padam.

d. Mengamankan sistem komputer dari gangguan-gangguan listrik yang dapat mengganggu sistem komputer baik berupa kerusakan software, data maupun kerusakan hardware.

e. UPS secara otomatis dapat melakukan stabilisasi tegangan ketika terjadi perubahan tegangan pada input sehingga tegangan output yang digunakan oleh sistem komputer berupa tegangan Yang stabil.

f. UPS dapat melakukan diagnosa dan management terhadap dirinya sendiri sehingga memudahkan pengguna untuk mengantisipasi jika akan terjadi gangguan terhadap sistem.

g. User friendly dan mudah dalam installasi.

h. Pengguna dapat melakukan kontrol UPS melalui jaringan LAN dengan menambahkan beberapa aksesoris yang diperlukan.

i. Dapat diintegrasikan dengan jaringan internet.

j. Notifikasi jika terjadi kegagalan dengan melakukan pengaturan perangkat lunak UPS management.

\subsection{Tipe Sistem UPS}

Analisis Penggunaan Uninterruptible Power Supply (Ups) Terhadap Pembebanan Daya

Stasiun Relay Rajawali Televisi Palembang

(Subianto) 
- Standby UPS

- $\quad$ Line Interactive UPS

- Double Conversion Online

- Delta Conversion Online

1. Continous UPS systems. Sistem UPS ini selalu bekerja mem-,,backup supply tenaga listrik sehingga pada sistem ini supply tenaga listrik selalu diubah ke supply DC kemudian diubah kembali menjadi supply tenaga AC melalui sebuah inverter.

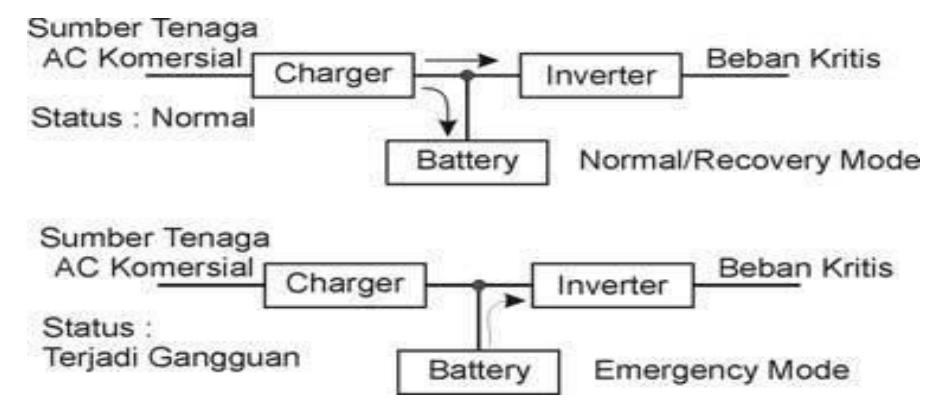

Gambar : Continous UPS system

2. Forward transfer UPS systems. Sistem ini akan bekerja menyuplai tenaga listrik ke beban ketika sensornya mendeteksi adanya gangguan supply tenaga listrik.

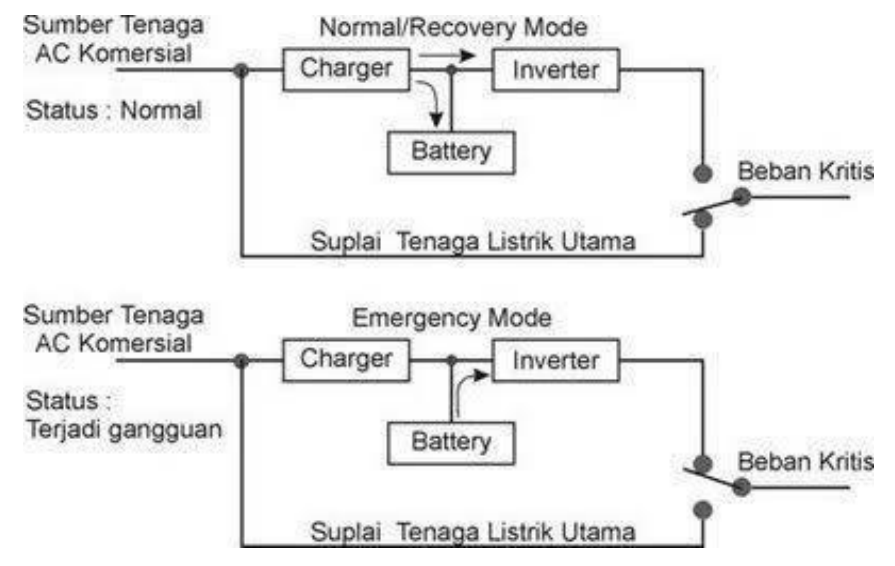

Gambar : Forward UPS system

3. Reverse transfer UPS systems. Pada sistem ini output sistem UPS langsung terhubung dengan beban kritis namun pada kondisi gangguan tertentu maka beban kritis dapat dialihkan pada sumber tenaga lain selain UPS.

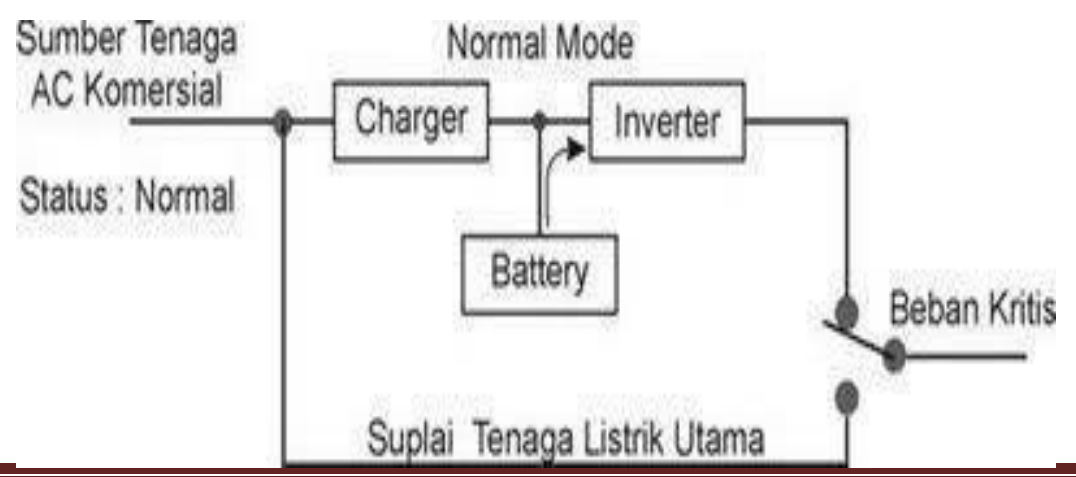

Analisis Penggunaan Uninterruptible Power Supply (Ups) Terhadap Pembebanan Daya Stasiun Relay Rajawali Televisi Palembang 


\section{METODELOGI PENELITIAN}

\subsection{Rating Pemutus Tenaga ${ }^{[1],[2],[4],[5] \&[6]}$}

1. Untuk sistem 1 phasa

$$
\text { In }=\frac{P}{V \mathrm{~L}-\mathrm{N} \cdot \cos \varphi}
$$

2. Untuk sistem 3 phasa

$$
\text { In }=\frac{P}{\sqrt{3} \cdot V \mathrm{~L}-\mathrm{L} \cdot \cos \varphi}
$$

\subsection{Daya dan Faktor Daya}

Di dalam sistem arus bolak-balik dibedakan daya/beban-beban listrik secara umum:

a. Daya aktif/nyata

$\mathrm{P}$ adalah kuantitas daya dan juga disebut sebagai daya nyata atau daya aktif. Daya aktif (P) yang digunakan adalah:
1. Satu phasa
$P=$ v.i. $\operatorname{Cos} \varphi$

2. Tiga phasa

$$
P=\sqrt{3} \text {.v.i. } \operatorname{Cos} \varphi
$$

Dimana :

$\mathrm{P} \quad=$ Daya aktif (watt)

$\mathrm{V}=$ Tegangan line to line (volt)

$\mathrm{I}=$ Arus (ampere)

$\operatorname{Cos} \varphi=$ Faktor Daya

b. Daya reaktif

Daya reaktif yang digunakan oleh suatu rangkaian adalah:

Daya reaktif $(\mathrm{Q})=$ arus $\mathrm{x}$ komponen $\mathrm{V}$ yang tegak lurus terhadap $\mathrm{I}$.

$\mathrm{Q}=\sqrt{3} \mathrm{~V} . \mathrm{I} \operatorname{Sin} \varphi$

c. Daya kompleks/semu

Dalam bentuk kompleks, daya dinyatakan sebagai:

$s=\frac{P}{\operatorname{Cos} \varphi}$

d. Daya semu $(\mathrm{S})=$ Tegangan $\mathrm{x}$ arus

$\mathrm{S}=\sqrt{3} \mathrm{~V} . \mathrm{I}$

e. Faktor Daya $(\operatorname{Cos} \varphi)$

Faktor Daya $(\cos \varphi)$ dapat dinyatakan dengan

$\operatorname{Cos} \varphi=\frac{P}{V \cdot I}=\frac{P}{S}=\frac{\text { watt }}{V A}$

Analisis Penggunaan Uninterruptible Power Supply (Ups) Terhadap Pembebanan Daya Stasiun Relay Rajawali Televisi Palembang 


\section{ANALISA DAN PEMBAHASAN}

\subsection{Data UPS ${ }^{[1],[2],[5] \&[6]}$}

Sistem UPS yang digunakan pada Stasiun Relay Rajawali Televisi Palembang adalah sistem UPS merk Riello Aros part number N4087made in Italy. Dengan konfigurasi fleksibel, aksesori dan opsional yang tersedia, sangat cocok untuk menyalakan beban kapasitif, seperti server blade. Keandalan dan ketersediaan satu daya untuk aplikasi kritis dijamin oleh paralel terdistribusi atau terpusat hingga 8 unit untuk $(\mathrm{N}+1)$ cadangan atau paralel daya, dan oleh semua berbagai konfigurasi yang tersedia dalam rentang MASTER MPS.

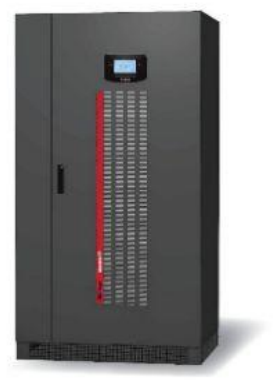

\subsection{Battery Systems}

\section{Gambar : UPS System - Riello Aros part number N4087}

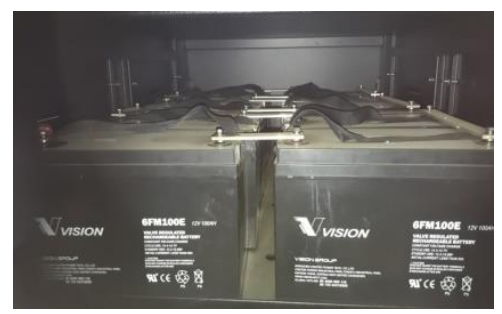

Gambar : Battery unit

Terdapat 40 battery unit yang digunakan sebagai tempat penyimpanan daya/energi cadangan untuk mensuplay mesin pemancar dan peralatan pendukungnya di Stasiun Relay Rajawali Televisi Palembang.

Untuk mengakomadasi daya listrik pada Stasiun Relay Rajawali Televisi Palembang, terdapat transformator yang dihubungkan ke genset. Spesifikasi transformator yang digunakan adalah 550kVA 3P 13,8kV/208V. Dari sini didapatkan tegangan keluaran dari transformator yang merupakan tegangan masukan (volt input AC) ke Stasiun Relay Rajawali Televisi Palembang dan UPS adalah 208V. Sehingga tegangan keluaran dari UPS yang masuk ke server/load di Stasiun Relay Rajawali Televisi Palembang adalah $208 \mathrm{~V}$ ( $\mathrm{V}_{\mathrm{L}-\mathrm{L}} 3$ Phasa).

\subsection{Perhitungan}

Data dan besaran yang akan dianalisa dan dihitung, antara lain:

1. Beban (load) UPS: berupa server yang terhubung ke UPS

Beban UPS yang ada di Stasiun Relay Rajawali Televisi Palembang adalah berupa mesin pemancar televisi, mixer audio, mixer video dan komputer. Perlu diketahui tegangan dan arus yang mengalir masuk/input ke beban, sehingga dapat dihitung total daya beban dalam VA (daya semu) dan Watt (daya aktif). Dalam mendistribusikan daya dari UPS di Stasiun Relay Rajawali Televisi Palembang, tegangan keluaran (output) 120kVA dari UPS dibagi ke beberapa peralatan, antara lain: 
1. Mesin Pemancar Televisi $=90,9 \mathrm{~A}$

2. Mixer Audio $=2,95 \mathrm{~A}$

3. Mixer Video $=2,72 \mathrm{~A}$

4. Komputer $=1,13 \mathrm{~A}$

\section{Arus Beban}

- Total arus beban (load)

$=\mathrm{I}_{\text {Load }}=90,9+2,95+2,72+1,13=97,7$ Ampere

- Total server yang terhubung pada UPS (status ON)

$=$ Total Server $=4$ unit

- Rata - rata arus per server :

$$
\begin{aligned}
\text { Rata }- \text { rata arus per server } & =\frac{I_{\text {load }}}{\text { Total Server }} \\
& =\frac{97,7 \text { Ampere }}{4}=24,425 \text { ampere }
\end{aligned}
$$

\section{Daya Beban}

Untuk mendapatkan total daya beban (total load) menggunakan persamaan daya semu 3 phasa: $\quad s=\frac{P}{\operatorname{Cos} \varphi}$

Atau:

$$
\begin{aligned}
& \mathrm{S}=\sqrt{3} \cdot \mathrm{V}_{\mathrm{L}-\mathrm{L}} \cdot \mathrm{I}(\mathrm{VA}) \\
& \mathrm{VL}-\mathrm{L}=\sqrt{3} \cdot \mathrm{VL}-\mathrm{N} \\
& \mathrm{S}=\sqrt{3} \cdot \sqrt{3} \cdot \mathrm{V}_{\mathrm{L}-\mathrm{N}} \cdot \mathrm{I} \\
& \mathrm{S}=3 \cdot \mathrm{V}_{\mathrm{L}-\mathrm{N}} \cdot \mathrm{I} \quad \text { (VA) }
\end{aligned}
$$

Diketahui:

$$
\begin{aligned}
& \mathrm{V}_{\mathrm{L}-\mathrm{N}}=120 \mathrm{~V} \\
& \mathrm{I} \quad=\mathrm{I}_{\text {Load }}=24,425 \mathrm{~A} \\
& \operatorname{Cos} \varphi=0,92
\end{aligned}
$$

Sehingga didapatkan total daya beban (total load) semua server yang terpasang pada UPS di Stasiun Relay RTV:

$$
\begin{aligned}
\mathrm{S} & =3 \cdot \mathrm{V}_{\mathrm{L}-\mathrm{N}} \cdot \mathrm{I} \\
& =3 \cdot 120 \mathrm{~V} \cdot 24,425 \mathrm{~A} \\
& =8 \cdot 793 \mathrm{VA} \\
\mathrm{P} & =\mathrm{S} \cdot \operatorname{Cos} \varphi \\
& =8.793 \mathrm{VA} \cdot 0,92 \\
& =8089,56 \mathrm{Watt}
\end{aligned}
$$

\section{UPS Rating Ideal}

UPS rating harus lebih besar dari load VA, minimal 20-25\% lebih besar dari load VA). Sehingga untuk mendapatkan UPS dengan rating ideal, tambahkan $25 \%$ ke total load VA lalu gunakan UPS dengan rating yang sama atau lebih besar dari jumlah tersebut.

Dengan total load $=25128$ VA, maka kapasitas daya UPS/UPS rating yang idealnya diperlukan (mengingat biaya, efisiensi, efektifitas dan runtime yang diperlukan): 
UPS rating ideal $\quad=$ Total load $+25 \%$. Total load

$$
\begin{aligned}
& =8793+25 \% .8793 \\
& =10,991 \mathrm{VA}
\end{aligned}
$$

Jadi, gunakan UPS dengan rating >= 10,991 VA, misalnya: $0.010991 \mathrm{kVA}$.

\section{Kapasitas dan Kemampuan UPS Sebelum Berbeban}

a. Daya atau UPS rating

Kapasitas daya $($ UPS rating $)=120 \mathrm{kVA}$

b. Arus Maksimal

Untuk mendapatkan kapasitas/total arus $\left(\mathrm{I}_{\max }=\mathrm{I}_{\mathrm{n}}\right)$ yang bisa ditampung UPS:

$$
\begin{aligned}
& I_{\text {max }}=I_{n}=\frac{s}{3 \cdot V_{L-N}} \\
& I_{\text {max }}=I_{n}=\frac{s}{3 \cdot V_{L-N}} \\
& I_{\text {max }}=I_{n}=\frac{S}{3 \cdot V_{L-N}}
\end{aligned}
$$

Diketahui:

$$
=\text { UPS rating }=70000 \mathrm{VA}=120 \mathrm{~V}
$$

Sehingga didapatkan total arus/arus maksimal $\left(\mathrm{I}_{\max }=\mathrm{In}\right)$ yang bisa ditampung UPS:

$I_{\max }=I_{n}=\frac{70000}{3 \times 120}=194.44$ ampere

\section{Kapasitas dan Kemampuan UPS Setelah Berbeban}

a. UPS Runtime

Saat terjadi kegagalan listrik, perlu diketahui lama waktu UPS dapat bertahan dan tetap hidup (UPS runtime) agar sesuai dengan kebutuhan sistem Stasiun Relay Rajawali Televisi Palembang selama peralihan listrik dari mulai mati listrik sampai listrik hidup kembali atau menggunakan generator set. UPS runtime harus lebih besar dari kebutuhan waktu.

Battery Capacity (based on batt enclosure) $=192 \mathrm{~V}$ x $167 \mathrm{~A} \times 1 \mathrm{~h}=32064 \mathrm{VAh}$

Setelah mendapatkan battery capacity, sehingga bisa didapatkan runtime :

$$
\begin{aligned}
\text { Runtime } & =\frac{\text { Battery Capacity }(V A h)}{\text { Total Load }(V A)} \times 60 \mathrm{~min} \\
& =\frac{32064 \mathrm{VAh}}{25128 \mathrm{VA}} \times 60 \mathrm{~min} \\
& =76,56 \text { menit }=1 \mathrm{jam} 17 \text { menit }
\end{aligned}
$$

b. Persentase Beban (Load) UPS

Analisis Penggunaan Uninterruptible Power Supply (Ups) Terhadap Pembebanan Daya Stasiun Relay Rajawali Televisi Palembang

(Subianto) 
Kapasitas daya (UPS rating) $=70 \mathrm{kVA}$ Untuk mendapatkan \% Load UPS.

$\%$ Load UPS $=\frac{\text { Total Load }(V A)}{\text { UPS Rating }(V A)} \times 100 \%$

$\%$ Load UPS $=\frac{25128 V A}{70000 V A} \times 100 \%=35.897 \%$

\section{Beban (Spare) yang Masih Bisa Ditampung UPS}

a. Arus yang masih bisa ditampung UPS : jumlah arus beban yang masih bisa dipasang/ditampung oleh UPS saat ini Arus yang masih bisa ditampung UPS.

$=I_{\max }-I_{\text {Load }}=194.44-69.8=124.64$ ampere

b. Jumlah server yang masih bisa ditampung UPS : jumlah beban atau server baru yang masih bisa dipasang/ditampung oleh UPS saat ini Jumlah server masih bisa ditampung UPS:

Jumlah server yang masih bisa ditampung UPS $=$

Jumlah server yang masih bisa ditampung UPS $=\frac{\text { Arus yg masih bisa ditampung UPS }}{\text { Rata }- \text { rata arus per server }}$

Jumlah server yang masih bisa ditampung UPS $=\frac{124.64}{1.108}=112.5$ Unit

c. Jika diperlukan penambahan daya UPS terhadap total beban server yang ada saat ini: dari hasil perhitungan UPS rating ideal (>=31410 VA) didapatkan bahwa UPS rating saat ini (70kVA) adalah oversizing UPS sehingga tidak diperlukan lagi penambahan daya UPS.

d. Jika terdapat penambahan server baru di kemudian hari: dapat mengacu pada poin b (jumlah server yang masih bisa ditampung UPS).

\section{Kondisi Ideal UPS 70kVA}

Didapat \% Load UPS $=35,897 \%$ sehingga masih terdapat spare sebesar $=100 \%-35,897 \%=$ $64,103 \%$. Spare $64,103 \%$ ini bisa dipakai secara maksimal sehingga menggunakan semua kapasitas daya UPS sebesar 70kVA. Akan tetapi untuk mendapatkan hasil ideal, UPS rating harus lebih besar dari load VA, minimal 20-25\% lebih besar dari load VA). Untuk mendapatkan UPS dengan rating ideal, tambahkan $25 \%$ ke total load VA lalu gunakan UPS dengan rating sama atau lebih besar. Sehingga dengan UPS rating saat ini $=70 \mathrm{kVA}$ didapatkan perhitungan sebagai berikut:

Kapasitas daya UPS ideal yang bisa dipakai

$=$ UPS Ratting $\times \frac{100}{100+25}$

$=70000 \times \frac{100}{100+25}$

$=56000 \mathrm{VA}$

a. Arus maksimal UPS ideal

$$
\begin{aligned}
& I_{\text {max }} \text { UPS ideal }=\frac{\text { Kapasitas Daya yang Dipakai }}{3 . V_{L-N}} \\
& I_{\text {max }} \text { UPS ideal }=\frac{56000}{3.120}=155.6 \text { ampere }
\end{aligned}
$$

Analisis Penggunaan Uninterruptible Power Supply (Ups) Terhadap Pembebanan Daya Stasiun Relay Rajawali Televisi Palembang 
b. Arus ideal yang masih bisa ditampung

UPS $\quad=I_{\max }=$ UPS Ideal $-I_{\text {Load }}=155,6-69.8=85,8$ Ampere

c. Jumlah server ideal yang masih bisa ditampung UPS:

Jumlah server yang masih bisa ditampung UPS

Jlh server yg masih bisa ditampung UPS $=\frac{\text { Arus ideal yg masi } \square \text { bisa ditampung UPS }}{\text { Rata }- \text { rata arus per server }}$

Jlh server yg masih bisa ditampung UPS $=\frac{85.8}{1.108}=77.4$ Unit

\subsection{Rekapitulasi Perhitungan}

Tabel : Rekapitulasi Perhitungan Analisisis Sistem UPS di RTV Palembang

\begin{tabular}{|l|l|l|}
\hline No. & \multicolumn{1}{|c|}{ Kategori } & \multicolumn{1}{|c|}{ Hasil } \\
\hline 1. & Total Arus Beban (load) & 69,8 Ampere \\
\hline 2. & Total Server yang terhubung ke UPS & 4 unit \\
\hline 3. & Rata-rata arus per server & 24,425 Ampere \\
\hline 4. & Total Daya Beban (load) & 8089,56 Watt \\
\hline 5. & UPS Rating Ideal & 10,991 VA \\
\hline 6. & Kapasitas Daya UPS Rating & $120 \mathrm{kVA}$ \\
\hline 7. & Arus Maksimal & 194,44 Ampere \\
\hline 8. & UPS Runtime & 1 jam 17 menit \\
\hline 9. & Persentase Beban (load) & $35,897 \%$ \\
\hline 10. & Arus yang masih bisa ditampung UPS & 124,64 Ampere \\
\hline 11. & Jumlah server yang masih bisa ditampung UPS & 112,5 \\
\hline 12. & Kapasitas daya UPS ideal & $56000 \mathrm{VA}$ \\
\hline 13. & Arus Maksimal UPS ideal & 55,6 Ampere \\
\hline
\end{tabular}

\section{PENUTUP}

Dari hasil Analisa dan Perhitungan diperoleh suatu kesimpulan yaitu :

1. UPS capacity (rating) untuk menentukan beban (load) max yang bisa dipasang.

2. Battery capacity menentukan lama UPS bisa hidup tanpa listrik atau on-battery (UPS runtime).

3. UPS load di Stasiun Relay Rajawali Televisi Palembang sebesar 35,9\% (terpakai 25,128 kVA dari $70 \mathrm{kVA}$ ), masih dapat dilakukan penambahan beban/server yang lebih banyak lagi.

4. UPS runtime sebesar 1 jam 17 menit, waktu ini lebih dari cukup untuk peralihan sumber listrik ke generator set.

5. UPS rating harus lebih besar dari load VA, minimal 20-25\% lebih besar. Untuk medapatkan UPS dengan rating ideal, tambah $25 \%$ ke total load VA, gunakan UPS dengan rating sama atau lebih besar.

Analisis Penggunaan Uninterruptible Power Supply (Ups) Terhadap Pembebanan Daya

Stasiun Relay Rajawali Televisi Palembang

(Subianto) 
6. UPS rating di Stasiun Relay Rajawali Televisi Palembang memiliki daya yang lebih besar dari UPS rating ideal (oversizing UPS). Ini dilakukan untuk mendapatkan runtime yang lebih lama dan jika ada penambahan server.

\section{DAFTAR PUSTAKA}

[1]. Abdul, 1998, Transformator; Pradnya Paramita, Jakarta Pusat.

[2]. Abdillah Margiono, 2017, Sistem Uninterruptible Power Sistem (Ups) Sebagai Sumber Daya Listrik Cadangan, Yayasan Kemajuan Teknik: Jakarta Pusat

[3]. Bonar.2012. Proteksi sistem Tenaga Listrik. Yogyakarta

[4]. Yuniansyah. 2016. Evaluasi Kerja Rele OCR di Penyulang Arwana Gardu Induk Sei. Kedukan. Skripsi. Fakultas Teknik, Universitas Palembang. Palembang

[5]. http://www.scribd.com/doc/64237756/Perhitungan-Kapasitas-Battery-Ups [diakses pada tanggal 30 mei 2018 pukul $19.00 \mathrm{WIB}]$

[6]. http://m2p.co.id/power_system.php [diakses pada tanggal 3 Juni 2018, jam 16.00 WIB] 